\title{
A GlobalizaÇão da IndiFERENÇA o Papel do Capital Soctal no Resgate Da ValorizaÇão Cidadã no Brasil
}

\section{Marcello Baquero ${ }^{1}$}

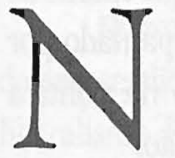

a tentativa de compreender os obstáculos que o Brasil enfrenta no processo de construção democrática, sobretudo no que diz respeito ao estabelecimento de uma cultura política participante e normativamente democrática, os cientistas sociais têm recorrido a enfoques teóricos alternativos aos tradicionalmente estabelecidos, particularmente o paradigma institucional. Entre as novas perspectivas teóricas que têm emergido nessadireçãopodem ser citadas: ademocraciadeliberativa de Habermas; a democracia radical de Mouffe; a democracia participativa de Pateman e a democracia reflexiva de Giddens. ${ }^{2}$ Estas teorias direcionaram suas análises para a revalorização do ser humano como protagonista do seu futuro. Nesse sentido, convergem para a valorização do princípio da participação política, não vendo o sujeito como mero espectador, mas como participante e com "voz" na arena política. Este tipo de democracia tem sido qualificado por alguns autores como "possuidora de uma sociedade civil vibrante".

Exemplos desse tipo de democracia são visíveis nos países desenvolvidos onde a base material (saúde, moradia, educação e transporte coletivo) já foi resolvida ou onde as desigualdades sociais são toleráveis, ou seja, não envolvem questões relativas à sobrevivência física, mas se referem a valores pós-materialistas (qualidade de vida e proteção do meio ambiente, entre outras). ${ }^{4}$

Embora os méritos dessas abordagens teóricas sejam evidentes, do ponto de vista

1 Professor do Programa de Pós Graduação em Ciência Política da Universidade Federal do Rio Grande do Sul. E-mail: baquero@orion.ufrgs.br.

2 Ver Habermas, J. The Theory of Communicative Action. Boston: Beacon Press; 1984 ; Moufre, C. O regresso do político. Lisboa: Gradiva, 1996; Pateman, C. Participação e teoria democrática. Rio de Janeiro: Paz e Terra, 1992; GIDdens, A. The constitution of society. Polity Press. Cambridge, 1984.

3 Ver BARBER. R.B. Clansmen, consumers, and citizens: theree takes on civil society. In:Fulawinder, R.K. (Ed.). Civil society, democracy and civic renewal. Boston: Rowman and Littlefield, 1999.

4 Ravvs, J. Uma teoria da justiça. São Paulo: Martins Fontes, 2002. 
da episteme, estão longe de serem aplicadas em países como o Brasil, onde os problemas de natureza material ainda não foram resolvidos, pois, a despeito dos avanços na dimensão da democracia formal, ${ }^{5}$ persistem graves problemas de concentração de renda edesigualdade social, os quais produzem exclusão social e a impossibilidade de resolver o crescimento da pobreza.

Nesse contexto, creio que reincidir na reprodução descontextualizada de paradigmas construídos em situações e condições diferentes das que encontramos no Brasil gera normativismos pouco úteis na busca de enfoques alternativos e aplicáveis para resolver os problemas sociais. A partir dessas reflexões pretendo, neste artigo, examinar os problemas que considero significativos para o desenvolvimento daquilo que chamo de democracia inercial, ou seja, um tipo de sistema político que, mesmo pautado por procedimentos poliárquicos, mantém vícios tradicionais e estruturais na política contribuindo para a sua estagnação e, até mesmo sua desinstitucionalização.

\section{A Primeira Distorção: a Perversidade da Globalização}

Nas últimas duas décadas, em virtude do predomínio de um pensamento único que privilegia o mercado como ente supremo regulador das relações sociais, plasmou-se a idéia de que se vive, atualmente, um período de paz mundial em que as nações, por meio da cooperação recíproca, buscam estabelecer um novo paradigma nas relações internacionais. No cenário interno das nações sugere-se que as mesmas nunca viveram uma época tão estável do ponto de vista do estabelecimento de regras e leis. Apressadamente, em minha opinião, tem-se concluído que se vive uma época de estabilidade política e democrática. Subjacente a esta constatação de otimismo, argumenta-se que têm surgido sociedades vibrantes, participativas, livres e autônomas.

Este discurso não encontra amparo quando analisados os principais indicadores sociais do país. Por exemplo, de acordo com dados da Pesquisa Nacional de Amostragem Domiciliar o número de indigentes e pobres no Brasil ultrapassa 71 milhões de pessoas e as perspectiva de uma diminuição nos próximos anosé remota. ${ }^{6}$ Essa crise se materializou, entre outros fatores, pela transferência maciça de renda dos grupos mais pobres para os grupos mais abastados, bem como a saída de capital para o mundo desenvolvido em virtude da consolidação do processo de globalização. Se o processo de globalização foi inevitável, gerando aspectos positivos que são inegáveis, no cômputo total os impactos

\footnotetext{
5 DaHl, R. Poliarquia. São Paulo: Edusp, 1997.

6 PNAD. Pesquisa Nacional por Amostra Domiciliar. Brasília, 2000.
} 
adversos são muito mais visíveis em países dependentes como o Brasil. Como exemplo dos aspectos perversos da globalização, salta imediatamente aos olhos o seu impacto na deslocalização e na desterritorialização. Ou seja, a mundialização ao mesmo tempo em que inclui também exclui. Assim, longe de gerar as bases que possibilitem a unificação do mundo, pelo contrário, a globalização o segmenta e o parcela. Nessas circunstâncias tornam-se evidentes as dificuldades em globalizar a política num sentido positivo.

Dessa forma, o Estado-Nação moderno que surge decorrente da globalização produz, pelo menos três consequiências na arena política, a saber: a) Uma crise de representação da política advinda do papel crescente dos meios de comunicação e informaçãa; b) 0 aparecimento de movimentos sociais de novo tipo e o deslocamento do público; e, c) 0 deslocamento da democracia de massas e o surgimento de um ideal democrático multicultural.

Nesse contexto, a política passa por uma transformação profunda, na qual o espetáculo político émais significativo do que o conteúdo dos debates. Outrossim, constatase a personalização dos acontecimentos: interessa a pessoa, o político e não seu programa, ou alianças políticas. Por outro lado, a estruturação da cultura política leva a que somente as más notícias sejam consideradas. A publicidade política tende a se concentrar nas imagens negativas, orientadas a destruir as propostas do oponente, enquanto o próprio programa é apresentado em termos gerais. A utilização dos escândalos políticos e sua difusão nos meios de comunicação são a arma fundamental dos atores políticos.

No que se refere aos novos movimentos de deslocamento do público, observa-se claramente uma crise de relevânciaede representatividadedasentidades tradicionaisde mediação política, principalmente os partidos políticos, sem falar dos sindicatos e entidades de classe. Nesse cenário, os novos movimentos surgidos apartir das reivindicações das identidades diversas e locais se constituem num tipo de resposta aos processos de globalização que produziram uma crise de representação políticae consequiências excludentes.

Nesse sentido a primazia do mercado e sua lógica pragmática têm gerado um processo de despolitização da ingerência dos cidadãos no campo político. Dessa forma, democracia representativa, na sua versão tradicional, está em crise, levando a debates acirrados sobre a verdadeira natureza de uma democracia participativa.

Na democracia formal-poliárquica é o Estado (partidos, instituições públicas) que determina a subjetividade dos atores sociais e os enquadra em determinados parâmetros normativos que, geralmente, incluem destinos evocações históricas tradicionais e negativase, desse modo, transformam as massas em objeto de manipulações, clientelismos ou movimentos de massa. 0 resultadoéa emergênciade uma sociedadede massas sem cidadãos. 
Para o Brasil, o desafio colocado pelo processo de globalização é maior do que para outras nações, na medidaem quenãotem conseguido desenvolversuacapacidadedeterritorializar sua própria história-em outras palavras, sua capacidadepara controlar os fatores que incidem nasua evolução - como entidade soberana nas dimensões territorial, social, cultural e política. Defato, aglobalização possibilitou odeclínio dessa capacidadese levadaem conta adependência em relação às forças do mercado global, sobre o qual opaís tem pouca ou nenhuma influência, pois a mobilidade do capital reduz a capacidade do Estado para domesticar o mercado e a economia. Por outro lado, ele também não consegue diminuir a transnacionalização e a crescentedependência internacional do Estado, reduzindo asua capacidade de regulação social. O resultadodessasituaçãoéa deconsolidação daidentidade nacional eadificuldadededesenvolver uma identidade nacional e um sentimento real de cidadania e solidariedade social. Em síntese, o chamado G-7 (Grupo dos Sete), que domina a estrutura global, não possui um projeto de democracia, de justiça social, de desenvolvimento e de conhecimento científico e humanístico realmente sério.' Por essa razão, as identidades coletivas alternativas se reforçam a partir do desafio da globalização e da crise do Estado-nação, mas o fazem de forma precária e pouco eficiente.

\section{A Segunda Distorção: Uma Sociedade Pluralista?}

Não hádúvida de que a abertura da economia brasileirapara as forças da globalização redundou em impactos desiguais napopulação, beneficiando os grupos econômicos tradicionais e penalizando a grande maioria. Para combater essa situação, a solução postulada é 0 aprofundamento e aperfeiçoamento da democracia. Embora o crescimento econômico seja fator essencial no resgate social de uma nação, a história mostrou também que a mera existência de crescimento econômico, no interior de um modelo político tradicional, acaba reproduzindo os esquemas de concentração de renda existentes.

Essa situação se agrava em virtude do empenho do governo em pagar a dívida externa sem contar com recursos suficientes. As tentativas de aumentar a arrecadação não tiveram êxito, pois nem as privatizações, nem os esforços exportadores podem funcionar quando o custo é a precarizaçãa do mercado nacional. Até o presente, a evidência mostra que a desnacionalização do setor público não redundou na melhoria da qualidade de bens e serviços ou no estabelecimento de um processo de competição comercialeqüitativa e salutar. Pelo contrário, constata-se o aumento do desemprego e da exclusão social,

7 Casanou, P. G. O colonialismo global e a democracia. Rio de Janeiro: Civilização Brasileira, 1995. 
particularmente devido à retração crescente do Estado em investir na dimensão social. Nesse contexto, o avanço da economia de mercado coincide com a promoção agressiva de uma concepção formalista institucional da democracia. Um sistema político concebido nesses termos é compatível com a degradação das condições de vida de grande parte da população, pois o lucro gerado para os mais poderosos nessas economias é o mais importante, sendo raramente aplicado na produção e distribuição de riquezas.

É a partir dessa lógica que se deve buscar explicações para a manutenção de uma cultura política fragmentada na qual se perpetuam os fatores histórico-estruturais que geram relações sociais baseadas em práticas tradicionais e negativas. Para ilustrar esse ponto, a história nos mostra que o sistema histórico social brasileiro, da mesma forma que nos países em desenvolvimento, nasce marcado por contradições. A superaçã̃o dessas contradições levou, eisto era lógico, na época, a privilegiar a dimensão formal-institucional da democracia, deixando em segundo plano os aspectos sociais. 0 problemaé que quando a perspectiva poliárquica da democracia entra em declínio, caracterizando uma crise de representatividade (os conflitos não conseguem mais ser resolvidos pelos mecanismos institucionais vigentes), cria-se um vazio, gerando a necessidade de pensar em formas alternativas de mediação política. É o que alguns autores têm chamado de novas institucionalidades. ${ }^{8}$ Nessa perspectiva, argumenta-se que as instituições políticas e seus procedimentos e mecanismos não conseguem mais dar conta dos fundamentos da mediação entre o ser humano e sua sociedade, razão pela qual os indivíduos se deslocam, se isolam e se alienam cada vez mais.

Tal situação, de natureza psíquica, se agrava pelas condições econômicas vigentes, o que redunda, segundo dados de pesquisa de opinião realizadas nos últimos anos, no desaparecimento do otimismo, instalando-se, no seu lugar, a incerteza e a angustia dos cidadãos. ${ }^{9} \mathrm{Em}$ tais circunstâncias, a probabilidade de fortalecer as práticas democráticas é remota. 0 pluralismo democrático está longe de se constituir numa realidade. Em suma, construir uma cultura política orientada por padrões de valorização das instituições políticas é algo que não está ocorrendo. Pelo contrário, o que se tem constatado é 0 surgimento de novas formas de poder à margem do Estado de Direito, mas que, paradoxalmente, detêm amplo poder sobre populações localizadas. Exemplo disto é 0 poder do narcotráfico e das gangues no país.

A consequiência de tal cenário é a corrup̧̧ão da democracia, pois tais agentes

8 PRA, JUSSARA R. (Re) socializar é preciso: Aportes para uma releitura sobre gênero e juventude no Brasil. In: BaqueRo, M. (oRG.). Democracia, Juventude e Capital Social no Brasil. Porto Alegre: Editora da UrRos, 2004. pp. 79-119.

9 Ver Latinobarômetro (1996; 2000; 2002); Encuesta Panamericana (2000); Pesquisa EsEB, (2002). 
atuam em detrimento de uma inclusão cidadã e constrangem mecanismos que possibilitem uma maior participação das pessoas na política. ${ }^{10}$ Este tipo de sistema político acaba por criar uma situação na qual o regime democrático-poliárquico convive com um governo oligárquico. Ou seja, ao mesmo tempo em que se verifica a existência de procedimentos formais da democracia representativa tais como constituição, partidos políticos, regras e leis; enfim, procedimentos democráticos, os mesmos são controlados, dominados e governados por poderes patrimonialistas de pessoas, grupos ou setores minoritários. ${ }^{11}$ Então, não é surpresa que a partir dessa situação se difunda, entre a maioria dos cidadãos, na sociedade brasileira, imagens, atitudes e comportamentos cada vez mais pessimistas e de incerteza sobre o futuro. 0 modelo que emerge nesse contexto é o de um total desapego pela política, visto que o aumento do desemprego, das desigualdades, da violência e da deterioração da qualidade de vida, somados à frustração com as promessas não cumpridas pelos governos eleitos, não motivam qualquer tipo de participação política.

Éclaro que o revigoramento do cidadão e da sociedade para o desempenho de um papel mais ativo não passa somente pela eliminação do componente organizacional da política ou a promoção de uma participação individual, mas por uma sinergia desses dois componentes. E a maior parte dos autores que examinam essa questão propõe o conceito de Capital Social como o mecanismo que pode gerar um processo de fortalecimento das pessoas, de tal forma que se possa resolver o problema da ação coletiva, fortalecendo não só a predisposição dos cidadãos a participar, mas, sobretudo, promovendo uma base normativa de apoio à democracia social.

\section{À Guisa de Conclusão}

A persistência da pobreza e da exclusão social no Brasil tem produzido novas linhas de reflexões para enfrentar esses problemas. Os anos 1990 mostraram uma tendência à descentralização e a um aumento da relevância do governo local. Nesse sentido, o tema da governança assume papel central, na medida em que desloca o Estado de sua situação de ser o único provedor do bem-estar, para um papel no qual atua como facilitador ou regulador das relações sociais.

10 Sanches-Parga, J. Politica, Transformaciones del conflicto, decline de los movimientos sociales y teoria del gobierno. Ecuador Debate n 53, p.19-40. Agosto, 2001.

$"$ Ver FAORo, R. Os donos do poder: formação do patronato político brasileiro. São Paulo, Globo, 1993; NunEZ, E. 0.A gramática política do Brasil: clientelismo e insulamento burocrático. Rio de Janeiro. Jorge Zahar, Brasília, ENAP, 1997; DAMATTA, R. Reflexões sobre o público e o privado no Brasil: um ponto de vista perverso. In: Cadernos de Ciências Sociais, Puc-Minas. Belo Horizonte, v. 3, n. 3, abril, 1993, p. 51-62. 
Fruto desse movimento, a teoria do Capital Social surge como a moldura para compreender e analisar as relações e conexões entre diferentes atores sociais envolvidos no desenvolvimento da comunidade. A premissa básicaé a de que a promoção da confiança interpessoal e a confiança política - elementos-chave do conceito de Capital Social podem ajudar a estabelecer novas bases de um contrato social fundamentado na igualdade e na eqüidade.

Para alcançar este objetivo são necessárias três condições, a saber: a) potenciar o papel dos cidadãos na vida associativa com uma conduta mais ética ecívica; b) articular um conjunto de normas já estabelecidas pelo Estado, que exijam um melhor comportamento das associações e; c) criar incentivos e medidas compensatórias que estimulem as associações a atuar de maneira mais prudente, altruísta e com autocontrole. No âmago desses elementos está o princípio norteador das novas sociedades que estão se formando, ou seja, a constituição de uma sociedade civil dinâmica e participativa. Há um consenso generalizado de que, nas sociedades modernas, o seu bem-estar e a sua habilidade para competir no mercado mundial são condicionados por uma única característica cultural: o nível de confiança inerente numa sociedade. ${ }^{12}$

Da mesma forma, a história do país tem mostrado que, de uma maneira geral, os procedimentos democráticos, os quais são fundamentais, em muitas oportunidades têm se transformado em barreiras e obstáculos para uma reestruturação efetiva do Estado numa dimensão social. Assim sendo, esses procedimentos têm freqüentemente contribuído para institucionalizar a corrup̧̧ão.

Ilustrativo dessa situação é a forma como foi concebido e difundido o princípio da estabilidade que, no fundo, esteve baseado no abandono progressivo da democracia e da política como meios de melhoria social em direção a uma nova forma de política, a qual reificou o capital e o mercado em detrimento da democracia, levando à legalização da instabilidade, à incerteza e ao medo. Segundo Oslak, ${ }^{13}$ a legitimidade da estabilidade foi coercitiva e implicou na renúncia a tudo o que estivesse fora da estabilidade. Isto significou a materializaçã̃o da exclusão social apoiada por uma perspectiva perversa do processo de globalização.

Sair dessa situação implica em investir pesadamente na dimensão social. A esse respeito existe clareza, presentemente, de que o melhor indicador do futuro para os cidadãos, organizações, regiões ou nações, éo estoque de Capital Social de que se dispõem.

\footnotetext{
12 Putnam, R. Making democracy work. Princeton. Princeton University Press, 1993.

13 Oszus, 0. Políticas públicas e regimens políticos: reflexiones a partir de algunas experiencias latinoamericanas. http://www.top.org,ar/Documentos/OSZLAK,\%200scar\%20- Acessado em 07/06/2004.
} 
Celso Furtado, há mais de duas décadas, afirmava que o desenvolvimento de um paísé, antes de mais nada, "principalmente um processo de ativação e canalização de forças sociais, da melhoria da capacidade associativa, do exercício da iniciativa e da inventividade. Portanto trata-se de um processo social e cultural, e, secundariamente, econômico. 0 desenvolvimento se produz quando se manifesta na sociedade uma energia capaz de canalizar, de forma convergente, forças que estavam latentes ou dispersas". ${ }^{14}$

Recebido em setembro de 2004.

${ }^{14}$ FuRtado, C. Conversaciones Sociales y desarrollo regional. Citado em Potocnjak, C. e Vignolo, C. Construyendo capital social em la región de Aysen, Chile: hacia uma interpretación del desarrollo como fenómeno conversacional. VII Congresso Internacional del CLAD Sobre la Reforma del Estado y de la Administración Pública. Lisboa, Portugal. De 8 a 11 de outubro de 2002. p.12. 